Check for updates

Cite this: RSC Adv., 2021, 11, 19196

\title{
TLC-smartphone in antibiotics determination and low-quality pharmaceuticals detection $\uparrow$
}

\author{
Asmaa G. Gad, ${ }^{a}$ Yasmin Mohammed Fayez, ${ }^{\text {b }}$ Khadiga M. Kelani ${ }^{\mathrm{ab}}$ \\ and Amr M. Mahmoud (D)*b
}

Thin layer chromatography (TLC) is a powerful and simple technique for screening and quantifying low quality and counterfeit pharmaceutical products. The detection methods used to detect and quantify separate analytes in TLC ranges from the densitometric method to mass spectrometric or Raman spectroscopic methods. This work describes the development and optimization of a simple and sensitive TLC method utilizing a smartphone CCD camera for verification of both identity and quantity of antibiotics in dosage form, namely ofloxacin and ornidazole. Mixtures of ofloxacin and ornidazole were chromatographed on a silica gel $60 \mathrm{~F}_{254}$ plate as a stationary phase. The optimized mobile phase is $n$ butanol : methanol : ammonia ( $8: 1: 1.5$ by volume). lodine vapor has been used as a "universal stain" to visualize the spots on the TLC plates in order to obtain a visual image using the smartphone camera and a desk lamp as an illumination source, thus eliminating the need for a UV illumination source. The recorded images were processed to calculate the $R_{\mathrm{f}}$ values $\left(R_{\mathrm{f}}\right.$ values for ofloxacin and ornidazole were 0.12 and 0.76 , respectively) which provide identity of the drugs while spot intensity was calculated using a commercially available smartphone app and employed for quantitative analysis of the antibiotics and "acetaminophen" as an example of a counterfeit substance. The smartphone TLC method yielded a linearity of ofloxacin and ornidazole in the range of $12.5-62.5 \mu \mathrm{g} / \mathrm{band}$ and $500-1000 \mu \mathrm{g} / \mathrm{band}$, respectively. The limit of detection was found to be $1.6 \mu \mathrm{g} / \mathrm{spot}$ for ofloxacin and $97.8 \mu \mathrm{g} / \mathrm{spot}$ for ornidazole. The proposed method was compared with the bench top densitometric method for verification using a Camag TLC Scanner 3, the spot areas were scanned at $320 \mathrm{~nm}$. The $R_{\mathrm{f}}$ value of ofloxacin and ornidazole was calculated to be 0.12 and 0.76 , respectively. The densitometric method yielded a linearity of ofloxacin and ornidazole in the range of $5-40 \mu \mathrm{g} / \mathrm{band}$ and $5-50 \mu \mathrm{g} / \mathrm{band}$, respectively. The limit of detection was found to be $0.8 \mu \mathrm{g} / \mathrm{spot}$ for ofloxacin and $1.1 \mu \mathrm{g} / \mathrm{spot}$ for ornidazole. The proposed method has been successfully applied for the determination of ofloxacin and ornidazole present in more than one pharmaceutical dosage form and was comparable to the densitometric method.

rsc.li/rsc-advances

\section{Introduction}

Low-quality medicine is a major problem for patients in developing countries, and it is estimated that 1 in 10 medical products in low- and middle-income countries is substandard or falsified. ${ }^{1-3}$ Counterfeit medications may contain falsified medication where no active pharmaceutical ingredient (API) is added or substandard APIs (wrong amount of the correct active ingredient), substituted by other cheaper and incorrect APIs (for example acetaminophen $)^{4}$ or even toxic substances. ${ }^{5}$ Low-quality pharmaceuticals have a negative impact on the patient's health as the incorrect drug

${ }^{a}$ Analytical Chemistry Department, Faculty of Pharmacy, Modern University for Technology and Information, Cairo, Egypt

${ }^{b}$ Analytical Chemistry Department, Faculty of Pharmacy, Cairo University, El-Kasr ElAini Street, 11562 Cairo, Egypt. E-mail: amr.bekhet@pharma.cu.edu.eg

$\dagger$ Electronic supplementary information (ESI) available. See DOI: 10.1039/d1ra01346g might make the patient's condition worse, or even kill them. Moreover, for antibiotic dosage form, the absence or low active ingredient content may result in the emergence of drug-resistant bacterial strains. ${ }^{6}$ Antimicrobial resistance (AMR) is the ability of a microbe to resist the effects of medication that once could successfully treat the microbe. ${ }^{7}$ The term antibiotic resistance is a subset of AMR, as it applies only to bacteria becoming resistant to antibiotics. ${ }^{\mathbf{8} 9}$ Resistant microbes are more difficult to treat, requiring alternative medication, and combination or higher doses of antimicrobials. These approaches may be more expensive, more toxic or both. ${ }^{\mathbf{1 0}}$

For the developing countries there is an urge for developing rapid, robust and low-cost techniques for identification of lowquality pharmaceuticals. Ideally, such detection technique can be able to detect falsified or substandard medicines. Thin layer chromatographic (TLC) method is ideal for this task and has been employed for detecting counterfeit medication, recent advances have been recently reviewed. ${ }^{11}$ TLC (and HPTLC) can 
be regarded as a simple but, in many cases, effective technique with similar performance to HPLC. TLC detection methods enable both qualitative information by utilizing the characteristic $R_{\mathrm{f}}$ values; and quantitative data by various techniques. ${ }^{12}$ Recently, cheap and widely available detection methods such as scanner, smartphones CCD camera, ${ }^{13}$ etc. have been employed. The detectors capture the color produced on the TLC plate and gauge the intensity of color using image-processing software. The intensity is then computed in regression equation obtained from calibration curve to get the concentration of the drug. ${ }^{14} \mathrm{CCD}$ smartphone cameras in particular are gaining more interest as detectors for colorimetric and TLC plates. Smartphone has been used for reading TLC plates to detect counterfeit drugs and even detection of illicit substance (i.e. cocaine) under UV lamp as source of illumination to visualize the analyte of interest. ${ }^{15,16}$ Using UV lamp as a visualization method for TLC adds extra cost for detection in developing and resource-limited areas; moreover, it is only limited to aromatic and conjugated compounds. Iodine has been used as universal method for TLC plate visualization, with the advantages of being widely available, cheap and "semi-destructive" as complexation is reversible and $\mathrm{I}_{2}$ will eventually evaporate. Moreover, there are indicators for visualizing the TLC plate that are specific for certain functional groups, such as nitro group like (acidified potassium permanganate, methanolic potassium hydroxide). It's worth mentioning that an innovative approach has been recently developed to visualize HPTLC plates using multiple illumination sources (in both UV and visible range) and images collected by smartphone CCD camera followed by data manipulation utilizing chemometrics, thus enabled HPTLC clustering/fingerprint. ${ }^{17}$

Ofloxacin is a broad spectrum antibiotic belonging to the fluoroquinolone class, ${ }^{18,19}$ its structure is shown in Fig. 1a. It inhibits bacterial cell division by inhibiting DNA gyrase, a type II topoisomerase, and topoisomerase IV, which is an enzyme necessary to separate replicated DNA. ${ }^{20}$ Ornidazole is an antibiotic of the imidazole class; ${ }^{21}$ its structure is shown in Fig. 1b. Ornidazole enters the cell by diffusion where the nitro group is reduced by redox proteins present only in anaerobic organisms to reactive nitro radical which exerts cytotoxic action by damaging DNA and other critical biomolecules. ${ }^{22,23}$ DNA helix destabilization and strand breakage has been observed. The binary mixture of ofloxacin and ornidazole is used for treatment of bacterial \& parasitic infections. It is used to treat gastrointestinal infections such as acute diarrhea or dysentery, gynecological infections, lung infections and urinary infections. $^{24}$ There are many reported RP-HPLC, ${ }^{25-27}$ HPTLC, ${ }^{26,28}$ capillary zone electrophoresis, ${ }^{29,30}$ voltammetry, ${ }^{31}$ HPLC $^{32,33}$ UPLC tandem mass spectrometry ${ }^{34}$ and spectrophotometry ${ }^{24,35}$ methods for the estimation of ofloxacin and ornidazole from binary pharmaceutical preparations or biological fluids.

In this contribution, we describe the development of easy, cost-effective, fast, green and convenient method 'to identify the presence of the correct active pharmaceutical ingredients with the stated concentration of each antibiotic drug in the dosage form' in resource limited areas. Hence, TLC method was employed for separating the antibiotics, visualization of TLC plates was adopted and CCD smartphone camera was employed as detector and finally processing the image with commercially available app software. The proposed method has been applied and compared to standard bench top densitometric method.

\section{Experimental}

\subsection{Apparatus}

- Samsung smartphone S5 CCD camera was used to collect the images.

- Camag Linomat 5 autosampler with Camag micro syringe $(100 \mu \mathrm{L})$; CAMAG, Muttenz, Switzerland.

- Camag TLC scanner 3 densitometer model 3 S/N 130319 equipped with wincats software for densitometric evaluation; CAMAG, Muttenz, Switzerland.

- Thin-layer chromatographic plates; pre-coated with silica gel $60 \mathrm{~F}_{254}, 20 \times 20 \mathrm{~cm}^{2}, 0.25 \mathrm{~mm}$ thickness (E. Merck, Darmstadt, Germany).

- UV lamp-short wavelength $254.0 \mathrm{~nm}$, Spectro line ${ }^{\circledR}$, model CM-10 (Westbury, New York, USA).

\subsection{Chemicals and reagents}

All chemicals and reagent used were of analytical grade. Methanol and $n$-butanol were obtained from Alfa chemical company. $\mathrm{NH}_{4} \mathrm{OH}$ was obtained from PioChem Company. Standards of OFL and ORN were obtained from National Organization for Drug \& Control Research. ORNI-O TM tablet was manufactured by India Acme Lite Tech-LLP. Batch number (ALT19317) was purchased from India. Each tablet is claimed to contain $500 \mathrm{mg}$ ORN and $200 \mathrm{mg}$ OFL as active ingredients.

\subsection{Prepared solutions}

2.3.1. Stock standard solutions. A weight equivalent to $10.0 \mathrm{mg}$ of either OFL or ORN were accurately weighted and

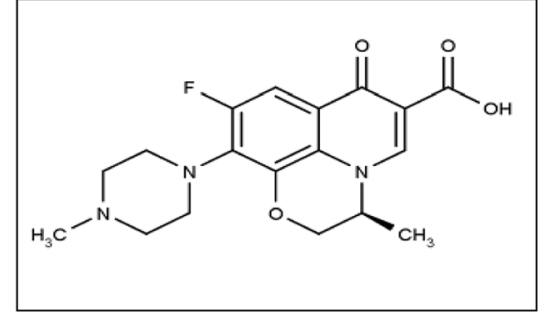

(a)

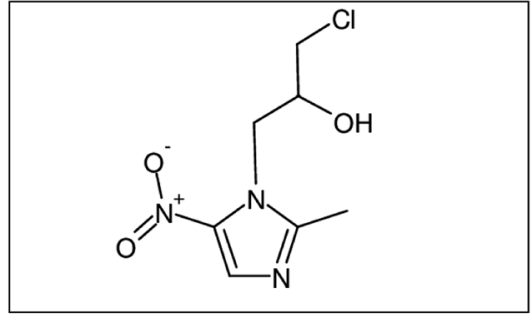

(b)

Fig. 1 (a) Chemical structure of ofloxacin and (b) chemical structure of ornidazole. 


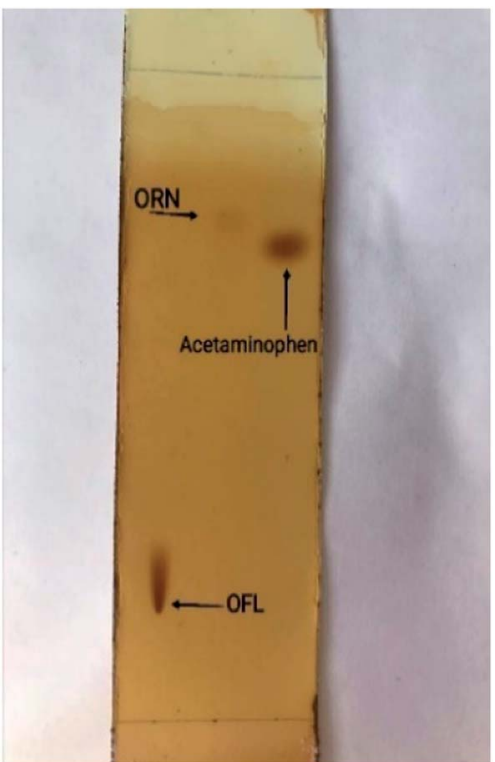

Fig. 2 TLC plate showing the three separated compounds; OFL, ORN, acetaminophen visualized with iodine.

transferred to $10 \mathrm{~mL}$ volumetric flask, dissolved and completed to the mark with the methanol to prepare final stock solution of concentration $\left(1 \mathrm{mg} \mathrm{mL}^{-1}\right)$ of the corresponding drugs.

2.3.2. Laboratory prepared mixtures. Different aliquots of OFL and ORN were accurately taken from their standard stock solutions to prepare mixtures containing different ratios of the two drugs.

\subsubsection{Chromatographic conditions}

2.3.3.1 Mobile phase. Different developing systems were tried, initially, (1) chloroform : ethyl acetate $(6: 4 \mathrm{v} / \mathrm{v})$, (2) chloroform : ethyl acetate : ammonia $(7: 3: 0.1$, by volume), and (3) $n$ butanol : methanol : ammonia ( $8: 1: 0.1$, by volume), OFL didn't move from the base line using the previous mentioned systems. By increasing the amount of ammonia to $1.5 \mathrm{~mL}$ in the (n-butanol : methanol : ammonia) system, OFL moved from the base line. Sharp and symmetric spots were obtained using (n-butanol : methanol : ammonia) ( $8: 1: 1.5$, by volume) as a developing system where good separation between OFL and ORN with sufficient difference in their $\left(R_{\mathrm{f}}\right)$ values without tailing of the separated bands.
2.3.3.2 Visualization of TLC plate. An "iodine chamber" was used for visualization by adding few crystals of solid iodine with powdered silica in a screw-capped TLC chamber. Then, the developed TLC plate $\left(5 \times 10 \mathrm{~cm}^{2}\right)$ was placed in the iodine chamber for 8 minutes until the spots appeared yellow-brown. After that we used, within 5 minutes, a smartphone camera to detect the intensity of each spot color appeared on the TLC plate using "Color Picker" freely available software application version is 5.0.6 (https://play.google.com/store/apps/details? id=gmikhail.colorpicker) and calculated intensity was utilized for the calibration curve construction for quantitative analysis and also, we made qualitative analysis for the detection of adulterant acetaminophen appearance. It's worth mentioning that iodine is known to be volatile as it sublimes easily, therefore, all the images were collected within 5 minutes once we removed the TLC plates out of the developing jar. The smartphone's rear-facing camera is aligned with a plate guide that places the TLC plate into focus and into the camera field of view. The distance from the camera to the plate is $10 \mathrm{~cm} .{ }^{36}$ The TLC plate background was white in color and we capture the image under desk lamp as a source of illumination.

TLC plates also were visualized by certain reagents that are selective for some functional groups, which represent another identification element besides using $R_{\mathrm{f}}$. To demonstrate that, on a separate plate we employed a selective method for detecting ORN based on visualization by dipping into acidified $\mathrm{KMnO}_{4}$ which gives light brown spots after drying, then the "Color Picker" application used to detect the intensity of each spot and calculated intensity was utilized for the calibration curve construction for quantitative analysis.

\subsection{Pharmaceutical dosage form}

In case of TLC-smartphone method, ten tablets were weighed, powdered and the average weight of one tablet was calculated. An accurately weighed powder equivalent to one tablet of ORNI$\mathrm{O}^{\mathrm{TM}}$ contains (200 and $500 \mathrm{mg}$ of OFL and ORN, respectively) was transferred to a $100 \mathrm{~mL}$ volumetric flask; dissolved in $60 \mathrm{~mL}$ methanol as a solvent and sonicated for 15 minutes, the volume was completed with methanol to obtain final concentration of $5000 \mu \mathrm{g} \mathrm{mL} \mathrm{mL}^{-1}$ of ORN and $2000 \mu \mathrm{g} \mathrm{mL} \mathrm{m}^{-1}$ of OFL. On the other hand, $1 \mathrm{~mL}$ was taken from previous flask and was diluted into

Table 1 The relation between luminance and different concentrations of OFL and ORN (12.5, 37.5, 50, 62.5 $\mu \mathrm{g} / \mathrm{band}),(500,600,700,900,1000$ $\mu \mathrm{g} / \mathrm{band})$, respectively

\begin{tabular}{llllll}
\hline Drug & $\begin{array}{l}\text { Concentrations } \\
(\mu \mathrm{g} / \text { band) }\end{array}$ & $\begin{array}{l}\text { Average luminance (average } \\
\text { of 3 replicates of the same spot) }\end{array}$ & $\begin{array}{l}\text { Standard deviation } \\
(\mathrm{SD})\end{array}$ & $\begin{array}{l}\text { Average luminance (average } \\
\text { of three replicates of 3 different spots) }\end{array}$ & $\begin{array}{l}\text { Standard deviation } \\
(\mathrm{SD})\end{array}$ \\
\hline \multirow{2}{*}{ OFL } & 12.5 & 14.3 & 0.5 & 14.4 & 0.6 \\
& 25 & 12.7 & 0.5 & 12.5 & 0.5 \\
& 37.5 & 10.7 & 0.5 & 10.73 & 0.5 \\
& 50 & 9 & 0.8 & 8.9 & 0.5 \\
ORN & 62.5 & 7 & 0.6 & 7.3 & 0.6 \\
& 500 & 34.3 & 0.5 & 34.7 & 0.6 \\
& 600 & 33.3 & 0.6 & 33.4 & 0.6 \\
& 700 & 31.3 & 0.5 & 31.4 & 0.5 \\
& 900 & 29.3 & 0.5 & 28.4 & 0.6
\end{tabular}


Table 2 Comparison between validation parameters of the proposed TLC-visualization method and TLC-densitometric method for determination of ofloxacin and ornidazole in their binary mixture

\begin{tabular}{|c|c|c|c|c|}
\hline \multirow[b]{2}{*}{ Parameters } & \multicolumn{2}{|l|}{ TLC-visualization method } & \multicolumn{2}{|c|}{ TLC-densitometric method } \\
\hline & OFL & ORN & OFL & ORN \\
\hline Wave length & & & $320.0 \mathrm{~nm}$ & $320.0 \mathrm{~nm}$ \\
\hline Linearity (regression equation) & $Y=-0.1466 x+16.183$ & $Y=-0.0171 x+43.553$ & $Y=434.5 x+10455$ & $Y=516.98 x+23107$ \\
\hline Slope ${ }^{a}$ & 0.15 & 0.02 & 434.5 & 516.9 \\
\hline Intercept $^{a}$ & 16.2 & 43.6 & 10455 & 23107 \\
\hline Specificity ${ }^{c}$ & & & $98.6 \pm 0.4$ & $100.5 \pm 1.5$ \\
\hline $\operatorname{LOD}(\mu \mathrm{g} / \mathrm{band})^{d}$ & 1.6 & 97.8 & 0.8 & 1.1 \\
\hline LOQ $\left(\mu \mathrm{g} / \mathrm{band}^{d}\right.$ & 4.9 & 296.3 & 2.3 & 3.3 \\
\hline Precision $( \pm \mathrm{RSD} \%)$ & & & & \\
\hline (a) Repeatability ${ }^{e}$ & \pm 0.8 & \pm 0.7 & \pm 0.4 & \pm 0.8 \\
\hline (b) Intermediate precision ${ }^{f}$ & \pm 0.4 & \pm 0.5 & \pm 0.3 & \pm 0.7 \\
\hline
\end{tabular}

${ }^{a}$ Average of three determinations. ${ }^{b}$ Accuracy (the mean of 5 different concentrations of each OFL and OR). ${ }^{c}$ Recovery of different laboratory prepared mixtures containing different ratios of OFL and OR. ${ }^{d}$ Limit of detection is determined via calculations, LOD $=(\mathrm{SD}$ of response/slope $)$ $\times 3.3 ; \mathrm{LOQ}=(\mathrm{SD}$ of response/slope $) \times 10{ }^{e}$ Intraday precision (the RSD of 3 different concentrations) $(10,20,25 \mu \mathrm{g} / \mathrm{band} \mathrm{for} \mathrm{OFL}) \&(5,10,50$ $\mu \mathrm{g} / \mathrm{band}$ for OR) in (TLC-densitometric) and $(12.5,25,37.5 \mu \mathrm{g} / \mathrm{band}$ for OFL) \& $(500,700,900 \mu \mathrm{g} / \mathrm{band}$ for OR) in TLC-smartphone, $3 \mathrm{replicates}$ each, within the same day. ${ }^{f}$ Interday precision (the RSD of 3 different concentrations) $(10,20,25 \mu \mathrm{g} / \mathrm{band}$ for OFL) \& (5, 10, $50 \mu \mathrm{g} / \mathrm{band}$ for OR) in (TLC-densitometric) and $(12.5,25,37.5 \mu \mathrm{g} / \mathrm{band}$ for OFL) \& (500, 700, $900 \mu \mathrm{g} / \mathrm{band}$ for OR) in TLC-smartphone, 3 replicates each, on 3 successive days.

Table 3 Determination of OFL and ORN in ORNI-OTM tablet by TLCsmartphone method and the TLC-densitometric

\begin{tabular}{lllll}
\hline $\begin{array}{l}\text { Pharmaceutical } \\
\text { formulation }\end{array}$ & \multicolumn{2}{l}{$\begin{array}{l}{ }^{a} \text { Recovery } \% \text { SD (TLC- } \\
\text { smartphone method) }\end{array}$} & $\begin{array}{l}{ }^{a} \text { Recovery } \% \pm \text { SD (TLC- } \\
\text { densitometric method) }\end{array}$ \\
\hline${ }^{b}$ ORNI-O ${ }^{\text {TM }}$ & OFL & ORN & OFL & ORN \\
& $99.1 \pm 0.7$ & $98.4 \pm 0.6$ & $98.3 \pm 0.5$ & $99.9 \pm 0.6$
\end{tabular}

${ }^{a}$ Average of three determinations. ${ }^{b}$ Batch no. ALT19317 (labeled to contain $200 \mathrm{mg}$ OFL and $500 \mathrm{mg}$ ORN).

$10 \mathrm{~mL}$ volumetric flask for analyzing ORN to obtain the volume of $500 \mu \mathrm{g} \mathrm{mL} \mathrm{m}^{-1}$ of ORN. Then $1 \mathrm{~mL}$ was taken from the last flask and was diluted into $10 \mathrm{~mL}$ volumetric flask for analyzing OFL to obtain the volume of $20 \mu \mathrm{g} \mathrm{mL} \mathrm{m}^{-1}$ of OFL.

In case of TLC-densitometric method, ten tablets were weighed, powdered and the average weight of one tablet was calculated. An accurately weighed powder equivalent to one tablet had been taken and then $0.01 \mathrm{~g}$ of ORNI-O ${ }^{\mathrm{TM}}$ tablet was weighted which equivalent to $(2000 \mu \mathrm{g}$ and $5000 \mu \mathrm{g}$ of OFL and ORN, respectively) and was transferred to $25 \mathrm{~mL}$ volumetric flask; dissolved in $10 \mathrm{~mL}$ methanol as a solvent and sonicated for 15 minutes, the volume was completed with methanol to obtain final concentration of $80 \mu \mathrm{g} \mathrm{mL}{ }^{-1}$ OFL and $200 \mu \mathrm{g} \mathrm{mL}^{-1} \mathrm{ORN}$. Then $1.25 \mathrm{~mL}$ was taken from the previous flask was diluted into $10 \mathrm{~mL}$ volumetric flask for analyzing OFL and ORN to obtain the volume of $10 \mu \mathrm{g} \mathrm{mL} L^{-1}$ of OFL and $25 \mu \mathrm{g} \mathrm{mL}^{-1}$ of ORN.

\section{Results and discussion}

The TLC visualization technique has many advantages as it is simple, low cost, rapid, available, portable and convenient in resources limited countries, no need for instrumentation or skilled technician, we used conventional TLC plates which is cheaper and we achieved TLC visualization using smartphone for detection and we were able to achieve comparable results by rationale optimization of the developing system, these advantages are on contrary of previous studies which use the HPTLC technique 'which is expensive and not readily available in the limited resource countries ${ }^{28}$ and which use smartphones with UV visualization. ${ }^{36}$ It is very convenient to use this technique in the resources limited countries to check if the drug product is adulterated or not without the need of using sophisticated instrumentation, just an image of a plate representing the chromatographic results with the detected spots for visual comparison of $R_{\mathrm{f}}$ values (identity) and intensities (drug content) to ensure that content in not sub-therapeutic dose.

TLC plate shows 3 spots of ofloxacin, ornidazole, and acetaminophen (commonly used adulterant) visualized with $\mathrm{I}_{2}$ after a run with the mobile phase ( $n$-butanol : methanol : ammonia) ( $8: 1: 1.5$, by volume) to determine the adulteration of the mixture OFL and ORN with acetaminophen rapidly as shown in Fig. 2. Both OFL and acetaminophen appear as brown spots, while ornidazole appears as a light brown spot. It worth nothing that specific and selective visualization of ORN can be performed with acidified $\mathrm{KMnO}_{4}$ reagent which produces yellow changes into light brown color, after drying, which is selective for nitro functional group.

The calculated $R_{\mathrm{f}}$ for OFL, ORN, acetaminophen is $(0.12$, $0.76,0.7)$, respectively so it's so easy and rapid determining the appearance of adulterant such as acetaminophen (qualitative analysis) only by making visualization with iodine and determine the $R_{\mathrm{f}}$ of each compound.

To test the capability of the proposed method for quantitative analysis of the antibiotics, we spotted five concentrations of ofloxacin $(12.5,25,37.5,50,62.5 \mu \mathrm{g} /$ band $)$ on a TLC plate and 


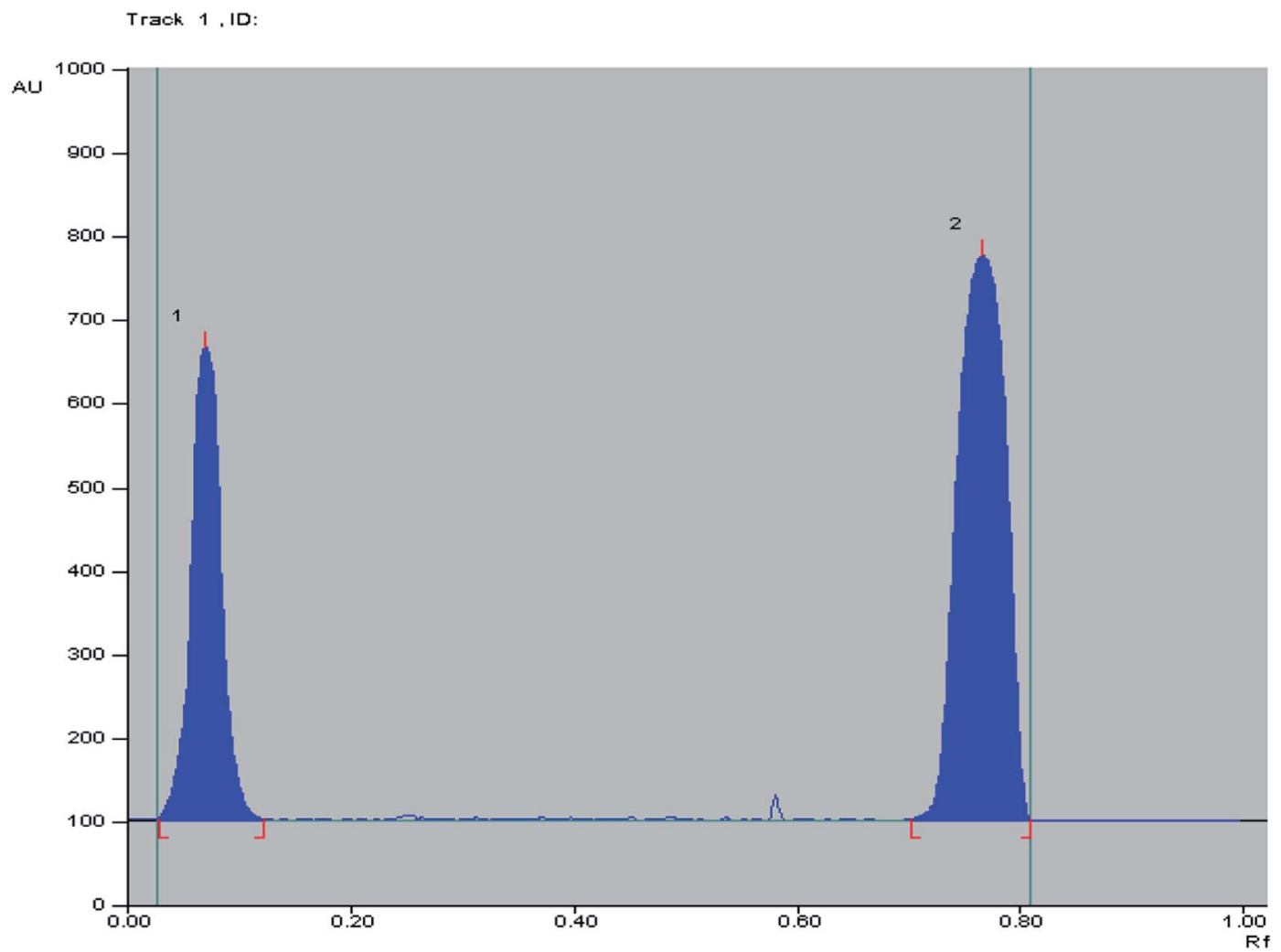

Fig. $32 \mathrm{D}$ TLC chromatogram of (1) ofloxacin $\left(R_{\mathrm{f}}=0.12\right)$ and (2) ornidazole $\left(R_{\mathrm{f}}=0.76\right)$, at $320.0 \mathrm{~nm}$ using $n$-butanol : methanol : ammonia $(8: 1: 1.5$, by volume) as a developing system.

visualized the separated spots with iodine and on the recorded image we determined the luminance of each spot using the "color picker" freely available software application as shown in Table 1.

Fig. S1a $\uparrow$ represents the relation between calculated luminance and OFL concentration. The relation between concentration of the drug and luminance is linear with $r=0.9999$ and we spotted five concentrations of ornidazole $(500,600,700,900$, $1000 \mu \mathrm{g} / \mathrm{band}$ ) on a TLC plate and visualized the separated spots with acidified $\mathrm{KMnO}_{4}$ and on the recorded image we determined the luminance of each spot using the "color picker" software application as shown in Table 1. Fig. S1b $\dagger$ represents the relation between calculated luminance and ORN concentration. The relation between concentration of the drug and luminance is linear with $r=0.9991$. This method is sensitive for determination of the antibiotics in their tablet as the concentration in tablet is high ( $200 \mathrm{mg}$ OFL \& $500 \mathrm{mg}$ ORN) but it would be challenging to determine these antibiotics in plasma as the concentration is smaller than TLC-smartphone CCD camera detection limit. Blank was performed on a TLC plates that have been exposed to iodine under the same conditions and the average luminance was 40.0 and the S. D was 0.6.

The validity of the proposed TLC-visualization method was achieved by means of LOD, LOQ, accuracy and precision as shown in Table 2.

The TLC-smartphone method was successfully applied for the determination of OFL and ORN in their combined pharmaceutical formulation (ORNI-O ${ }^{\mathrm{TM}}$ tablet) and the recovery results was $99.1 \pm 0.7$ for ofloxacin and $98.4 \pm 0.6$ for ornidazole as shown in Table 3.

The proposed method has been compared to the bench top TLC-densitometry method which is a useful technique for the resolution and in turn for the quantitative determination of drug mixtures. This method offers high sensitivity and selectivity for the analysis of OFL and ORN in the presence of each other without any interference in their pure form and in their pharmaceutical dosage form. Different developing systems were tried, chloroform : ethyl acetate $(6: 4 \mathrm{~V} / \mathrm{V})$, chloroform : ethyl acetate : ammonia $(7: 3: 0.1$, by volume), and $n$ -

Table 4 Determination of ofloxacin and ornidazole in their laboratory prepared mixtures by the TLC-densitometric method

\begin{tabular}{|c|c|c|}
\hline \multirow{2}{*}{$\frac{\text { Mix. ratio }}{\text { OFL : OR }}$} & \multicolumn{2}{|c|}{${ }^{a}$ Recovery\% } \\
\hline & OFL & ORN \\
\hline $10: 10$ & 98.1 & 100.8 \\
\hline $10: 20$ & 98.5 & 98 \\
\hline $20: 10$ & 98.5 & 100.6 \\
\hline $10: 25$ & 98.6 & 102.3 \\
\hline $40: 10$ & 99.3 & 100.7 \\
\hline Mean & 98.6 & 100.5 \\
\hline SD & 0.4 & 1.5 \\
\hline
\end{tabular}

${ }^{a}$ Average of three determinations. 
Table 5 Statistical analysis of the results obtained by the proposed method and the official method for the determination of OFL and ORN in pure powder form

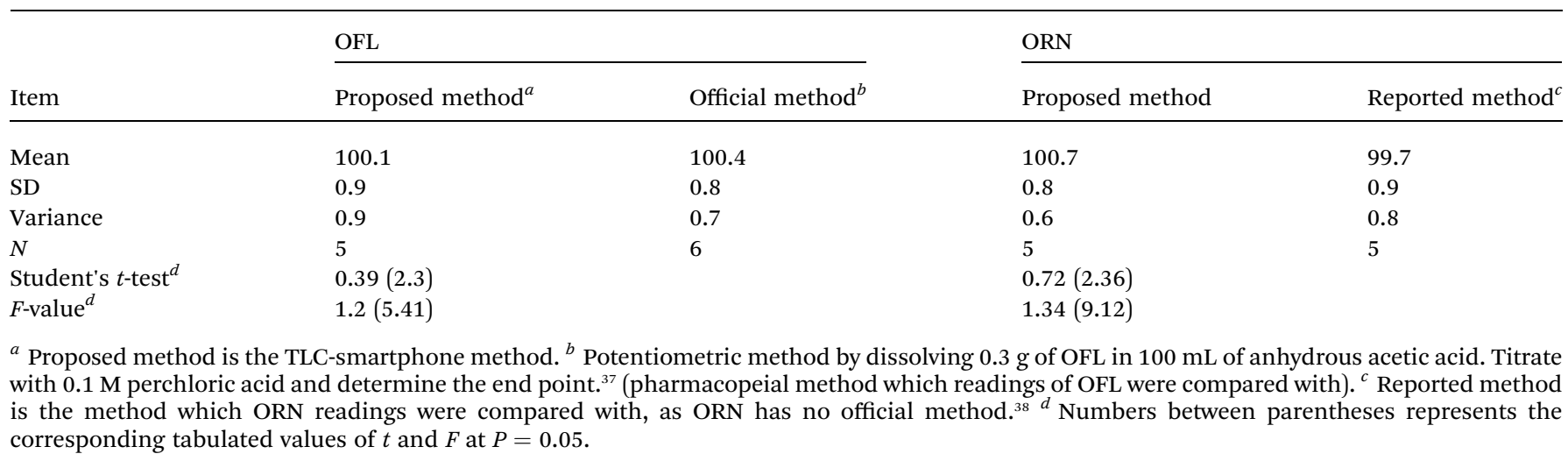

butanol : methanol : ammonia ( $8: 1: 0.1$, by volume), OFL didn't move from the base line using the previous mentioned systems. Increasing the amount of ammonia to $1.5 \mathrm{~mL}$ made the OFL moves from the base line. Sharp and symmetric spots were obtained using ( $n$-butanol : methanol : ammonia) ( $8: 1: 1.5$, by volume) as a developing system where good separation between OFL and ORN with sufficient difference in their $\left(R_{\mathrm{f}}\right)$ values without tailing of the separated bands as shown in Fig. 3 was obtained. Well defined bands were obtained when the chromatographic tank was previously saturated with the mobile phase for 20 minutes at room temperature. The instrumental conditions such as slit dimension and detection wavelengths were optimized. Detection at $\lambda 320 \mathrm{~nm}$ for both OFL and OR was suitable providing good sensitivity for determination of OFL and OR with minimal noise. TLC-densitometric scanning chromatograms of different concentrations of OFL and ORN were performed. Calibration curves were constructed representing the relationship between the obtained integrated peak areas and the corresponding concentrations in the range of (5$40 \mu \mathrm{g} / \mathrm{band}$ ) for OFL and (5-50 $\mu \mathrm{g} / \mathrm{band})$ for OR. Linear relationships were obtained as shown in Fig. S2a and b. $\dagger$ The regression equations were computed and found to be:

$$
\begin{gathered}
\mathrm{PA}_{\mathrm{OFL}} 320.0 \mathrm{~nm}=434.5 x+10455 r=0.9999 \\
\mathrm{PA}_{\mathrm{OR}} 320.0 \mathrm{~nm}=Y=516.98 x+23107 r=0.9999
\end{gathered}
$$

where PA is the integrated peak area at $320.0 \mathrm{~nm}$ for OFL and $\mathrm{OR}, x$ is the corresponding concentration in $\mu \mathrm{g} / \mathrm{band}$ and $r$ is the correlation coefficient.

The validity of the TLC densitometric method was achieved by means of LOD, LOQ, accuracy and precision as shown in Table 2. The results obtained from the laboratory prepared mixtures containing different ratios of OFL and ORN separated at specified conditions were presented in Table 4. The TLC-densitometric method was successfully applied for the determination of OFL and ORN in their combined pharmaceutical formulation (ORNI$\mathrm{O}^{\mathrm{TM}}$ tablet) and the recovery results was $98.3 \pm 0.5$ for ofloxacin and $99.9 \pm 0.6$ for ornidazole as shown in Table 3 .
Statistical comparison of the results obtained by the proposed method and those by applying the "official" and "reported" methods showed that there is no significant difference with respect to accuracy and precision as represented in Table 5 . Where the proposed method is the TLC-smartphone method. In case of OFL there is an "official" method (Pharmacopeial method), therefore it has been adopted for comparison, whereas, in case of ORN there is no official method so the "reported" densitometric method had been used to compare the ORN results with TLC-smartphone method.

\section{Conclusion}

Low quality medication in low-income countries represent a major challenge for healthcare system, therefore, developing simple, robust method for detecting low quality and counterfeit medications will have a major impact on population health. TLC separation method combined with simple $I_{2}$ visualization method and smartphone detection for capturing and analysis of the image has been proposed for both qualitative and quantitative determination of antibiotics drugs in bulk and pharmaceutical formulation. Furthermore, based on the specific functional group such as nitro, ornidazole can be independently identified in presence of other co-formulated drug and possible adulterant such as "acetaminophen". The method was compared to the benchmark densitometric method and no statistical difference was reported. This TLC separation plus smartphone detection method is very simple, cost-effective (no UV source is required) and more available so it can be extended to detect other antibiotics in pharmaceutical formulations.

\section{Conflicts of interest}

There are no conflicts of interest to declare.

\section{References}

1 A. Petersen, N. Held and L. Heide, PLoS One, 2017, 12(9), e0184165, DOI: 10.1371/journal.pone.0184165. 
2 S. M. Beargie, C. R. Higgins, D. R. Evans, S. K. Laing, D. Erim and S. Ozawa, PLoS One, 2019, 14(8), e0217910, DOI: 10.1371/ journal.pone.0217910.

3 E. Pisani, A. L. Nistor, A. Hasnida, K. Parmaksiz, J. Xu and M. O. Kok, Wellcome Open Res., 2019, 4, 70, DOI: 10.12688/ wellcomeopenres.15236.1.

4 A. A. Weaver, H. Reiser, T. Barstis, M. Benvenuti, D. Ghosh, M. Hunckler, B. Joy, L. Koenig, K. Raddell and M. Lieberman, Anal. Chem., 2013, 85(13), 6453, DOI: 10.1021/ac400989p.

5 P. N. Newton, M. D. Green and F. M. Fernández, Trends Pharmacol. Sci., 2010, 31, 99-101.

6 A. Johnston and D. W. Holt, Br. J. Clin. Pharmacol., 2014, 78(2), 218, DOI: 10.1111/bcp.12298.

7 J. Ali, Q. A. Rafiq and E. Ratcliffe, Future Sci. OA, 2018, 4, FSO290.

8 S. Metz-Gercek, R. Strauß, C. Rambaud, A. A. Adegoke, W. Adamus-Bialek and L. M. Durso, Advances in Antibiotic Resistance, 2019, 327, 1-28.

9 N. Kardos, SOJ Microbiology \& Infectious Diseases, 2017, 5, 121.

10 M. L. Cohen, Science, 1992, 257, 1050-1055.

11 J. Sherma and F. Rabel, J. Liq. Chromatogr. Relat. Technol., 2019, 42, 367-379, DOI: 10.1080/10826076.2019.1610772.

12 R. J. Ekiert, J. Krzek and W. Rzeszutko, Chromatographia, 2008, 67, 995.

13 I. Hussain, K. Ahamad and P. Nath, RSC Adv., 2016, 6, 2237422382, DOI: 10.1039/c6ra02483a.

14 L. F. Capitán-Vallvey, N. Lopez-Ruiz, A. Martinez-Olmos, M. M. Erenas and A. J. Palma, Anal. Chim. Acta, 2015, 899, 23-56.

15 F. Tosato, T. R. Rosa, C. L. M. Morais, A. O. Maldaner, R. S. Ortiz, P. R. Filgueiras, K. M. Gomes Lima and W. Romão, Anal. Methods, 2016, 8, 7632-7637, DOI: 10.1039/c6ay02126c.

16 H. Yu, H. Le, S. Lumetta, B. T. Cunningham, E. Kaale and T. Layloff, Proc. IEEE Sens., 2017, 125, 85-93, DOI: 10.1109/ ICSENS.2016.7808847.

17 L. Pieszczek and M. Daszykowski, Talanta, 2021, 221, 121599, DOI: 10.1016/j.talanta.2020.121599.

18 W. J. Munckhof, in Kucers the Use of Antibiotics: A Clinical Review of Antibacterial, Antifungal, Antiparasitic, and Antiviral Drugs, 7th edn, 2017, DOI: 10.1201/9781315152110.

19 X. Si, Y. Wei, C. Wang, L. Li and Y. Ding, Anal. Methods, 2018, 10, 1961-1967.
20 M. Iftekhar Hussain, A. Sarker, T. Begum, F. Hasin, F. Binte Farid Himu and M. Riazul Haque Shahin, J. Res. Pharmaceut. Sci., 2016.

21 P. Rutgeerts, G. Van Assche, S. Vermeire, G. D'Haens, F. Baert, M. Noman, I. Aerden, G. De Hertogh, K. Geboes and M. Hiele, Gastroenterology, 2005, 128, 856-861.

22 W. Raether and H. Hänel, Parasitol. Res., 2003, 90, S19-S39, DOI: $10.1007 / \mathrm{s} 00436-002-0754-9$.

23 A. Dublanchet and R. Durieux, Ann. Microbiol., 1980, 131, 4559.

24 D. M. Patel, J. A. Soneji, P. B. Patel and C. N. Patel, Pharm. Methods, 2012, 3, 102-105.

25 T. D. F. B. Y. RP-HPLC, Methods, 2010, 1, 78-83.

26 M. Puranik, D. V Bhawsar, P. Rathi and P. G. Yeole, Indian J. Pharm. Sci., 2010, 72, 513.

27 R. Singh, M. Maithani, S. K. Saraf, S. Saraf and R. C. Gupta, Eurasian J. Anal. Chem., 2009, 4(2), 161-167.

28 T. K. Ravi and N. Shukla, Indian J. Pharm. Sci., 2006, 68(6), 838-840, DOI: 10.4103/0250-474X.31033.

29 K. L. See, A. A. Elbashir, B. Saad, A. S. Mohamed Ali and H. Y. Aboul-Enein, Biomed. Chromatogr., 2009, 23, 12831290, DOI: 10.1002/bmc.1251.

30 B. Koppenhoefer, A. Jakob, X. Zhu and B. Lin, HRC J. High Resolut. Chromatogr., 2000, 23, 413-429, DOI: 10.1002/15214168(20000601)23:6<413::AID-JHRC413>3.0.CO;2-E.

31 S. A. Özkan, B. Uslu and H. Y. Aboul-Enein, Crit. Rev. Anal. Chem., 2003, 33(3), 155-181, DOI: 10.1080/713609162.

32 K. Lu and Q. Tong, Fenxi Ceshi Xuebao, 2011.

33 A. P. Dewani, R. L. Bakal, P. G. Kokate, A. V. Chandewar and S. Patra, J. AOAC Int., 2015, 98(4), 913-920, DOI: 10.5740/ jaoacint.14-189.

34 F. Tamtam, F. Mercier, J. Eurin, M. Chevreuil and B. Le Bot, Anal. Bioanal. Chem., 2009, 393, 1709-1718, DOI: 10.1007/ s00216-008-2576-9.

35 K. P. Bhusari and D. R. Chaple, Asian J. Res. Chem., 2009, 2, 60-62.

36 H. Yu, H. M. Le, E. Kaale, K. D. Long, T. Layloff, S. S. Lumetta and B. T. Cunningham, J. Pharm. Biomed. Anal., 2016, 125, 85-93, DOI: 10.1016/j.jpba.2016.03.018.

37 United States Pharmacopeial Convention, 2003 USP NF and USP NF 21, Rockville, MD.

38 P. N. Ranjane, S. V. Gandhi, S. S. Kadukar and K. G. Bothara, J. Chromatogr. Sci., 2010, 48(1), 26-28, DOI: 10.1093/ chromsci/48.1.26. 